\title{
Schistosomus reflexus in a Dog and a Cat
}

\author{
Paulo Henrique Leal Bertolo', Maria Eduarda Bastos Andrade Moutinho da Conceição', \\ Lucien Roberta Valente Miranda de Aguirra' ${ }^{2}$, Danielli Martinelli Martins'², Breno Costa de Macedo', \\ Leandro Nassar Coutinho², Adriana Maciel de Castro Cardoso² \& Washington Luiz Assunção Pereira²
}

\begin{abstract}
Background: Schistosomus reflexus (SR) is a congenital anomaly, that the animal presents exposed abdominal and thoracic organs. The alterations includes limbs malformation, abnormal spinal column, liver and diaphragm hypoplasia, genitourinary and gastrointestinal changes, on this way, the fetus can not survive. The aim of this study was to report the first SR case in dog and cat in Brazil, and describe anatomical, pathological and radiographic changes.

Case: The puppy had ventral midline defect in the abdominal and thoracic wall extending from the sternum to the pubis with viscera exposition, including the heart, lung, liver, stomach, intestine, spleen, kidneys, moreover right army was abnormal, however no spinal column was present. It was performed radiography to evaluate bone abnormalities, and was diagnosed agenesis of carpal, metacarpal and phalange bones. The kitten had ventral midline defect measuring $4 \times 2 \mathrm{~cm}$, in the abdominal wall and exposition of liver, stomach, intestine and spleen, as well as tibiotarsal joint arthrogryposis on both lags. It was performed fetus radiography and no spinal column change was diagnosed.

Discussion: Schistosomus reflexus is a congenital abnormality common in ruminants. Although it was few reported in dogs and cats. The two cases in this study are the firsts reposts in Brazil in these especies. In our case, the dog had exposition of abdominal and thoracic organs and died one hour after born, similar to this, another author reported a case where the thoracic and abdominal evisceration and the puppy died ten minutes after born. However, in another case with abdominal evisceration only, the puppy survived for eight days. Probably it happened because respiratore function was not compromised. The kitten had abdominal opening only, in turn, other authors reported a case whose abdominal viscera exposition was by pelvic fissure, and another case, what presented thoracic and abdominal evisceration, like our dog case. Some authors affirm that this defect causes fetal dystocia on ruminants, because of the vertebral column abnormality, what promote passage difficult at born moment. On the other hand, dogs did not present these kind of changes and dystocia was not related to this pathology on cases in dogs and cats, however most of these authors performed cesarean because the female did not get normal born. As well as, on two cases in kitten were reported vertebral column abnormalities, what can be related to dystocia. Even no animal of our study present any vertebral column abnormality, other bone changes were found, like carpal, metacarpal and phalange agenesis on army of the dog and tibiotarsal joint arthrogryposis on both lags of the cat fetus. The others report in dogs did not found vertebral column or bone changes, but in cats it was observed vertebral column abnormalities and other changes, like arthrogryposis on four limbs, skull flattening, mandibular brachignathism, reduced ossification of the cranial vault bones, palatoschisis and unfused eyelids. SR etiology is not clearly known, it may be related with genetic, mechanic, endocrine, metabolic, nutrition and infectious factors. The moment of embryonic development, where these factors influence the changes is related with abnormality grade. Although, Chromosomic abnormalities, like chromatid and chromosome breaks, non-homologous pairing of chromosomes was shown. In this study the bitch did not present any metabolic, endocrine or nutritional change, on other hand the queen was submitted to exogenous hormonal treatment to avoid pregnancy, what may be related to SR development. SR is a rare abnormality in dog and cat, fetus radiographic, anatomical and pathological findings confirmed to being this congenital defect, and this are the first reports in Brazil in these species.
\end{abstract}

Keywords: congenital defects, canine, feline, veterinary neonatology, congenital evisceration. 


\section{INTRODUCTION}

Schistosomus reflexus (SR) is a congenital anomaly, that the animal presents exposed abdominal and thoracic organs $[8,9]$. In some cases it can causes foetal dystocia, because conformational defects, and obstetric help or fetotomy is necessary [11].

The alterations includes limbs malformation, abnormal spinal column, liver and diaphragm hypoplasia, genitourinary and gastrointestinal changes [10,11], on this way, the fetus can not survive [8,9].

Etiology is not even known, although genetic, environment and infections are related, or more than one of them [9]. Chromosomic abnormalities, like chromatid and chromosome breaks, non-homologous pairing of chromosomes was shown in cats [10].

SR is more common in bovine [5,6,11], however it was reported in buffalo [13], ewe [2], goat [1,14], horse [12], rhinoceros [4], and few cases in cats [7,10] and dogs $[8,9]$. The aim of this study was to report the first SR case in dog and cat in Brazil, and describe anatomical, pathological and radiographic changes.

\section{CASES}

Case 1. A 2-year-old, female, Pinscher, primigravida was admitted at Veterinary Hospital. She was being in labor for $12 \mathrm{~h}$. First puppy was born after obstetric help. After $2 \mathrm{~h}$ it was observed fatigue, then she was submited to a cesarean and ovarohisterectomy. There were 2 fetus, both alive, one of them was normal, and another had ventral midline defect measuring 7 × 2 $\mathrm{cm}$, in the abdominal and thoracic wall extending from the sternum to the pubis with viscera exposition, including the heart, lung, liver, stomach, intestine, spleen, kidneys, moreover right army was abnormal, however no spinal column deformity was present (Figure 1A).

The puppy dead one hour after surgery. It was performed radiography to evaluate bone abnormalities, and was diagnosed agenesis of carpal, metacarpal and phalange bones, but no column abnormality was observed (Figure 1B).

Case 2. At same Veterinary Hospital of the first case was admitted a female feline, 3-year-old, cross breed, she had been in estrus 75 days before, after copulate it was administrated exogenous progesterone to avoid pregnancy.

Four days before clinical attendance the cat was being in labor, but had born no kitten. She presented anorexia, adipsia, apathy, abdomen was firm and big, on ultrasound evaluation it was diagnosed pregnancy with dead fetus.

It was performed cesarean and ovarohisterectomy, after that the fetus were evaluated and all of them was dead, although one presented abnormalities, as ventral midline defect measuring $4 \times 2 \mathrm{~cm}$ in the abdominal wall and exposition of liver, stomach, intestine and spleen, as well as tibiotarsal joint arthrogryposis on both lags (Figure 2A). It was performed fetus radiography and no spinal column change was diagnosed (Figure 2B).

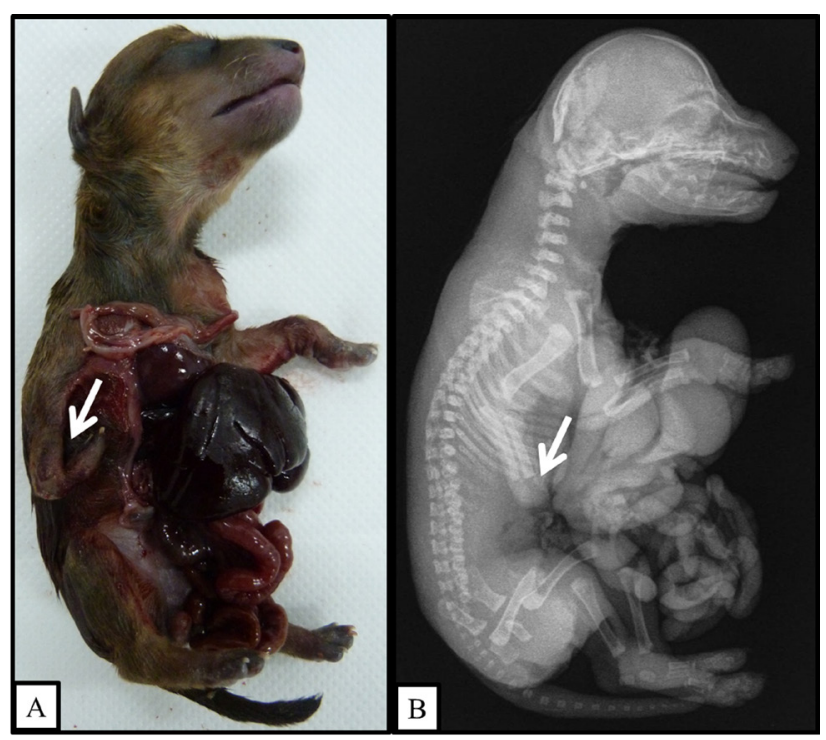

Figure 1. Puppy dog specimen, what presents Schistosomus reflexus. AMacroscopy evaluation shown ventral midline defect with $7 \times 2 \mathrm{~cm}$ in the abdominal and thoracic wall extending from the sternum to the pubis with viscera exposition, and abnormal formation of right army (arrow). B- Radiography shown agenesis of carpal, metacarpal and phalange bones (arrow).

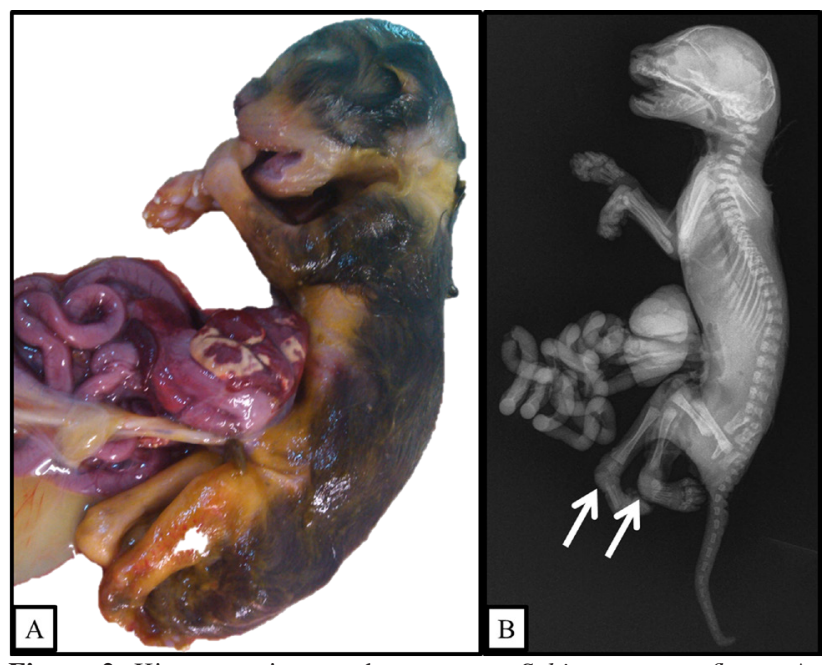

Figure 2. Kitten specimen, what presents Schistosomus reflexus. AMacroscopy evaluation shown ventral midline defect with $4 \times 2 \mathrm{~cm}$ in the abdominal wall with viscera exposition. Tibiotarsal joint arthrogryposis on both limbs. B- Radiography diagnosed the same arthrogryposis seen in macroscopy (arrows). 


\section{DISCUSSION}

SR is a congenital abnormality common in ruminants $[1,2,5,6,11,13,14]$. Although it was few reported in dogs $[8,9]$ and cats $[7,10]$. The two cases in this study are the firsts reposts in Brazil in these especies.

In our case, the dog had exposition of abdominal and thoracic organs and died one hour after born, similar to this, another author reported a case where the thoracic and abdominal evisceration and the puppy died ten minutes after born [9]. However, in another case with abdominal evisceration only, the puppy survived for eight days. Probably it happened because respiratore function was not compromised [8].

The kitten had abdominal opening only, in turn, other authors reported a case whose abdominal viscera exposition was by pelvic fissure [10], and another case, what presented thoracic and abdominal evisceration, like our dog case [7].

Some authors affirm that this defect causes fetal dystocia on ruminants, because of the vertebral column abnormality, what promote passage difficult at born moment $[1,2,5,11,14]$. On the other hand, dogs did not present these kind of changes and dystocia was not related to this pathology on cases in dogs and cats [7-10], however most of these authors performed cesarean because the female did not get normal born. As well as, on two cases in kitten were reported vertebral column abnormalities, what can be related to dystocia.
Even no animal of our study present any vertebral column abnormality, other bone changes were found, like carpal, metacarpal and phalange agenesis on army of the dog and tibiotarsal joint arthrogryposis on both lags of the cat fetus. The others report in dogs did not found vertebral column or bone changes [8,9], but in cats it was observed vertebral column abnormalities [10] and other changes, like arthrogryposis on four limbs, skull flattening, mandibular brachignathism, reduced ossification of the cranial vault bones, palatoschisis and unfused eyelids.

SR etiology is not clearly known, it may be related with genetic, mechanic, endocrine, metabolic, nutrition and infectious factors. The moment of embryonic development, where these factors influence the changes is related with abnormality grade [3]. Although, Chromosomic abnormalities, like chromatid and chromosome breaks, nonhomologous pairing of chromosomes was shown [10]. In this study the bitch did not present any metabolic, endocrine or nutritional change, on other hand the queen was submitted to exogenous hormonal treatment to avoid pregnancy, what may be related to SR development.

SR is a rare abnormality in dog and cat, fetus radiographic, anatomical and pathological findings confirmed to being this congenital defect, and this are the first report in Brazil in these species.

Declaration of interest. The authors report no conflicts of interest. The authors alone are responsible for the content and writing of the paper.

\section{REFERENCES}

1 Bello A., Sonfada M.L., Umar A.A., Ja'afar A.I., Abubakar M.S., Umaru M.A., Umar A., Raji A.A., Baraya Y.S. \& Abubakar A.A. 2012. Schistosomus reflexus in a red Sokoto doe. Scientific Journal of Zoology. 1(4): 79-81.

2 Ferreira D.O.L., Santarosa B.P., Monteiro-Toma C.D., Belotta A.F., Chiacchio S.B., Machado V.M.V., Gonçalves R.C. \& Prestes N.C. 2013. Estudo anatomorfológico, radiográfico e tomográfico de Schistosomus reflexus em ovino da raça Dorper: relato de caso. Arquivo Brasileiro de Medicina Veterinária e Zootecnia. 65(4): 1096-1102.

3 Jubb K.V.F., Kennedy P.C. \& Palmer N. 2007. Pathology of Domestic Animals. 5th edn. Oxford: M. Grant Maxie, 2340p.

4 Lankton J.S., Vanderhart D.J. \& Terrel S.P. 2014. Schistosomus reflexus-like malformation in a southern white rhinoceros (Ceratotherium simum simum). Journal of Zoo and Wildlife Medicine. 45(3): 708-711.

5 Laughton K.W., Fisher K.R.S., Halina W.G. \& Partlow G.D. 2005. Schistosomus reflexus syndrome: a heritable defect in ruminants. Anatomia Histologia Embryologia. 34(5): 312-318.

6 Macêdo J.T.S.A., Lucena R.B., Giaretta P.R., Kommers G.D., Fighera R.A., Irigoyen L.F. \& Barros C.S.L. 2011. Defeitos congênitos em bovinos da Região Central do Rio Grande do Sul. Pesquisa Veterinária Brasileira. 31(4): 297-306.

7 Mateo I. \& Camón J. 2008. Schistosoma reflexum in a cat: insights into aetiopathogenesis. Journal of Feline Medicine and Surgery. 10(4): 376-379.

8 Molina V.M., Oviedo C.A., Casado A. \& Arias M.P. 2012. Schistosomus reflexus en un canino: reporte caso. Revista de la Facultad de Medicina Veterinaria y de Zootecnia. 59(1): 49-55.

9 Öszoy S.Y., Oto C. \& Haziroglu R. 2009. Schistosoma reflexum in a dog. Ankara Üniversitesi Veteriner Fakültesi Dergisi. 56: 225-226. 
P.H.L. Bertolo, M.E.B.A.M. Conceição, L.R.V.M. Aguirra, et al. 2017. Schistosomus reflexus in a Dog and a Cat.

10 Ozalp G.R., Celikler S., Simsek G., Ozyigit M.O. \& Inan S. 2011. A case of Schistosoma reflexum in a cat with chromosomal aberrations. Reproduction in Domestic Animal. 46(2): 373-376.

11 Prestes N.C. \& Megid J. 2010. Uma forma rara de ocorrência do Schistosomus reflexus em bovino - relato de caso. Veterinária e Zootecnia. 17(2): 214-218.

12 Prestes N.C., Santos R.C. \& Leal L.S. 2011. Ocorrência do Schistosomus reflexus em equino (relato de caso). Brazilian Journal of Equine Medicine. 35: 12-14.

13 Purohit G.N., Kumar P., Solanki K., Shekher C. \& Yadav S.P. 2012. Perspectives of fetal dystocia in cattle and buffalo. Veterinary Science Development. 2(8): 31-42.

14 Suthar D.N., Sharma V.K., Dabas V.S. \& Bhoi D.B. 2011. Per-vaginal handling of Schistosomus reflexus as a cause of dystocia in a Goat. Veterinary World. 4(7): 330-331. 